\title{
Design and Analysis of 2N4416 n channel JFET Single Stage Amplifier for large bandwidth and low Voltage Gain
}

\author{
${ }^{* 1}$ Abdullahi Y, ${ }^{\mathbf{2}}$ A.A Sifawa, ${ }^{3}$ Sulu H.T, ${ }^{4}$ M.I Iliyasu \\ ${ }^{1,3,4}$ Department of Science Laboratory Technology, \\ Umaru Ali Shinkafi Polytechnic Sokoto, Nigeria \\ ${ }^{2}$ Department of Physics, Sokoto State University, Sokoto, Nigeria
}

\begin{abstract}
A bipolar junction transistor (BJT) is a current-controlled device, while a field-effect transistor (FET), is a voltage-controlled device, the bipolar transistor has two principal disadvantages. First, it has low input impedance because of the forward-biased emitter junction. Secondly, it has a considerable noise level. The field-effect transistor (FET) has a large input impedance which may be more than 100 megaohms, the FET is generally much less noisy than the ordinary or bipolar transistor. In this paper $2 N 4416 n$ channel JFET single-stage amplifier was designed, in order to analyze the circuit, important terms and main parameters were determined, the frequency response and bandwidth of the amplifier were also determined and discussed graphically using Multisim 14.2 simulator, the results characterized amplifier with large bandwidth and low voltage gain.
\end{abstract}

Keywords: Amplifier, Analysis, 2N4416, JFET n channel, Single Stage.

\subsection{INTRODUCTION}

The JFET stands for junction field effect transistor is a three terminal unipolar solid state device in which current is control by an electric field, there are two types of JFET, P channel and N channel JFET [1]. JFET have the following features: high input impedance, can be fabricated in small size area, it is a majority charge carrier device hence it has less noise, it is a low power consumption device, can be fabricated in small size area and occupies less space in circuits due to its smaller size [2]. Used as a switch, chopper, amplifier, buffer, in the oscillatory circuits because of its low frequency drift and in digital circuits such as computers and memory circuits because of their small size [2]. While BJT stands for bipolar junction transistor composed of $\mathrm{p} \mathrm{n}$ junctions, its operation involves two kinds of charge carriers holes and electrons [3]. A BJT or FET both shares the same category of transistors, having the property of both conduction and consists of three basic terminals [3]. JFET has better thermal stability and higher input impedance than BJT; for these FETs are preferred over BJTs for use as the input stage to a multistage amplifier [4].

Many authors carried out researchers on electrical components using different simulators software packages, some of them are: Fu et al. [5] carried out research on Power SiC D MOSFET Model Accounting for Non-uniform Current Distribution in JFET Region, finite - element simulations show that current saturation for a typical device geometry is due to 2-D carrier distribution effects in the JFET region caused by current spreading from the channel to the JFET region. Popelka et al. [6] carried out research on Effect of Neutron Irradiation on High Voltage 4H-SiC Vertical JFET Characteristics: Characterization and Modeling, the 2D physical model of JFET in ATLAS simulator was developed and calibrated including the neutron irradiation effects. Simulation showed a good agreement with experimental data. Jin et al. [7] carried out research on Optimized Design of Space Solar Array Simulator with Novel Three-Port Linear Power Composite Transistor Based on Multiple Cascaded SiC-JFETs, Space solar array simulators (SSASs), which are used for testing space power systems generally utilize linear power topologies owing to their fast dynamic performance and satisfactory simulation accuracy. Alnasser [8] carried out research on A Novel Low Output Offset Voltage Charge Amplifier for Piezoelectric Sensors using SPICE simulator, the proposed charge amplifier was assembled by using general purpose JFET Op-Amp to capture and amplify the output voltage of the piezoelectric vibration sensor Minisense100. Narang et al. [9] carried out a simulation study on Impact of Temperature Variations on the Device and Circuit Performance of Tunnel FET, with ATLAS device simulation software. Taeb et al. [10] carried out on Modeling and analysis of a nonlinear fully distributed FET using FDTD technique, the results achieved from MATLAB are compared with semi-distributed model which is simulated by ADS simulator However some of the simulators have difficulties for beginners, in that case Proteus or Multisim can be used for their simplicity and acceptable accuracy. This paper is aimed at a design of 2N4416 JFET $n$ channel single stage amplifier, which involves determination of the important terms, main parameters, frequency respond and bandwidth of the amplifier using Multisim 14.2 simulator. 


\subsection{DESIGN}

\subsection{The important terms to be determined}

In order to analyze the 2N4416 JFET circuit, the following important terms as shown in Figure 1 are to be determined:
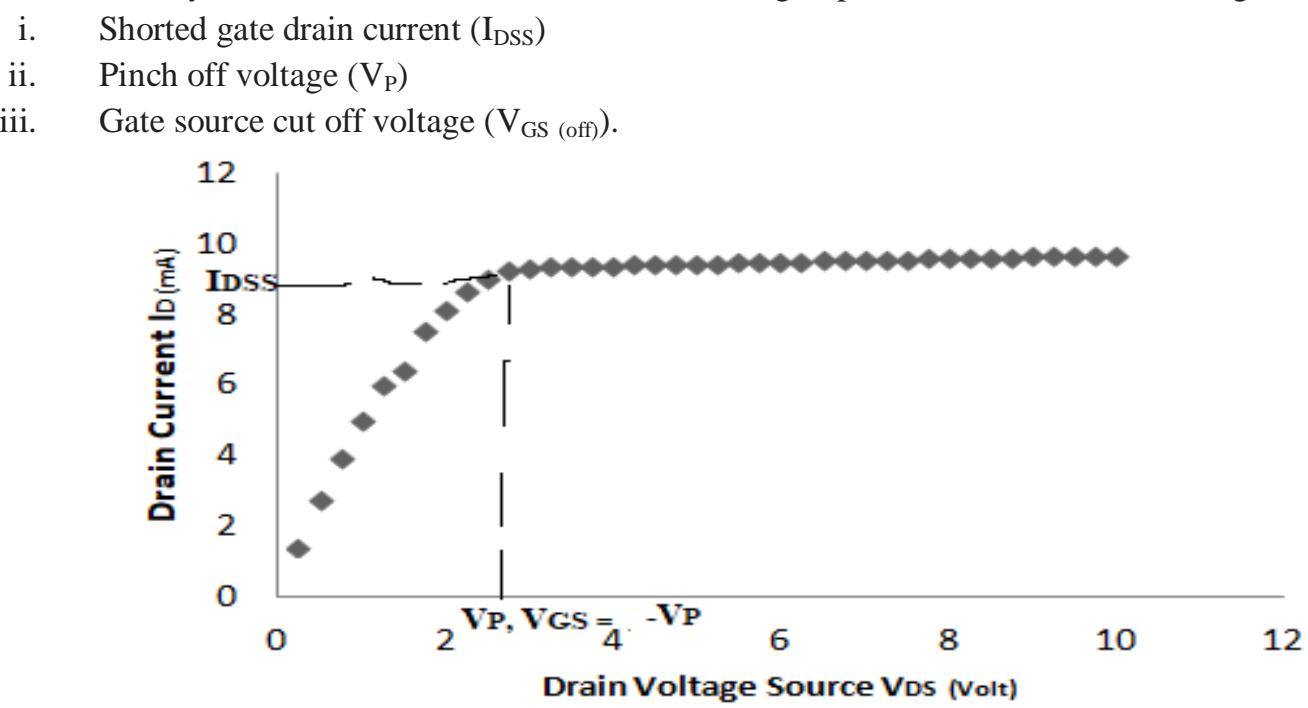

Figure 1: Relationship of Drain Current with Drain Voltage

\subsubsection{Shorted-gate drain current $\left(I_{D S S}\right)$}

It is the drain current with source short circuited to gate (i.e. $\left.\mathrm{V}_{\mathrm{GS}}=0\right)$ and drain voltage $\left(\mathrm{V}_{\mathrm{DS}}\right)$ equal to pinch off voltage, it is sometimes called zero bias current. The following points may be noted carefully [11]: (i) Since $\mathrm{I}_{\text {DSS }}$ is measured under shorted gate conditions; it is the maximum drain current that can be getting with normal operation of 2N4416 JFET. (ii) There is a maximum drain voltage $\left(\mathrm{V}_{\mathrm{DS}(\max )}\right)$ that can be applied to a 2N4416 JFET, if the drain voltage exceeds $\mathrm{V}_{\mathrm{DS} \text { (max) }} 2 \mathrm{~N} 4416$ JFET would breakdown (iii) The region between $V_{P}$ and $V_{D S \text { (max) }}$ (breakdown voltage) is called constant current region or saturation region, as long as $\mathrm{V}_{\mathrm{DS}}$ is kept within this range, $\mathrm{I}_{\mathrm{D}}$ will remain constant for a constant value of $\mathrm{V}_{\mathrm{GS}}$. In other words saturation region 2N4416 JFET behaves as a constant current device, for proper working of 2N4416 JFET it must be operated in the active region.

\subsubsection{Pinch off Voltage $\left(V_{P}\right)$}

It is the minimum drain source voltage $\left(\mathrm{V}_{\mathrm{DS}}\right)$ at which the drain current $\left(\mathrm{I}_{\mathrm{DSS}}\right)$ essentially becomes constant, for values of $\mathrm{V}_{\mathrm{DS}}$ greater than $\mathrm{V}_{\mathrm{P}}$ the drain current is almost constant it is because the channel is effectively closed and does not allow further increase in drain current. It is noted that for proper function of $2 \mathrm{~N} 4416 \mathrm{JFET}$, it is always operated for $V_{D S}>V_{P}$ however $V_{D S}$ should not exceed $\mathrm{V}_{\mathrm{DS}(\max )}$ otherwise 2N4416 JFET may breakdown [11].

\subsubsection{Gate source cut off voltage $\left(V_{\mathrm{GS} \text { (off }}\right)$}

It is the gate source voltage $\left(\mathrm{V}_{\mathrm{GS} \text { (off) }}\right)$ where the channel is completely cut off and the drain current becomes zero . Notes (i) it is interesting to note that $\mathrm{V}_{\mathrm{GS}}$ (off) will always have the same magnitude value as $\mathrm{V}_{\mathrm{P}}$ (ii) There is a distinct difference between $\mathrm{V}_{\mathrm{P}}$ and $V_{G S \text { (off). }} V_{P}$ is the value of $V_{D S}$ that causes the JFET to become a constant current device, it is measured at $V_{G S}=0 \mathrm{~V}$ and will have a constant drain current $=\mathrm{I}_{\mathrm{DSS}}$, however $\mathrm{V}_{\mathrm{GS} \text { (off) }}$ is the value of $\mathrm{V}_{\mathrm{GS}}$ that causes $\mathrm{I}_{\mathrm{D}}$ to drop to nearly zero [11], [12].

Mathematical analysis yields the following expression for drain current:

$\mathrm{I}_{\mathrm{D}}=\mathrm{I}_{\mathrm{DSS}}\left[1-\frac{\mathrm{v}_{\mathrm{GS}}}{\mathrm{V}_{\mathrm{GS} \text { (off })}}\right]^{2}$

Where $\mathrm{I}_{\mathrm{D}}=$ drain current at given $\mathrm{V}_{\mathrm{GS}}$

$\mathrm{I}_{\mathrm{DSS}}=$ shorted gate drain current

$\mathrm{V}_{\mathrm{GS}}=$ gate source voltage

$\mathrm{V}_{\mathrm{GS} \text { (off) }}=$ gate source cut off voltage .

Apart from important terms which have to be determined in order to analyze the 2N4416 JFET circuit, a 2N4416 JFET also has certain parameters which determine its performance in a circuit [12]. 
In order to analyze the performance of a 2N4416 JFET in the circuit following main parameters have to be determined:

(i) a.c drain resistance $\left(\mathrm{r}_{\mathrm{d}}\right)$

(ii) Transconductance $\left(\mathrm{g}_{\mathrm{m}}\right)$

(iii) Amplification factor $(\mu)$

\subsubsection{A.C drain resistance $\left(\mathbf{r}_{\mathbf{d}}\right)$}

It is the ratio of change in drain source voltage $\left(\Delta \mathrm{V}_{\mathrm{DS}}\right)$ to the change in drain current $\left(\Delta \mathrm{I}_{\mathrm{D}}\right)$ at constant gate source voltage. its unit is $\operatorname{Volt}(\mathrm{V}) / \operatorname{Ampare}(\mathrm{A})$, expressed as [12]:

$\mathrm{r}_{\mathrm{d}}=\frac{\Delta \mathrm{V}_{\mathrm{DS}}}{\Delta \mathrm{I}_{\mathrm{D}}} \quad$ at constant $\mathrm{V}_{\mathrm{GS}}$

\subsubsection{Transconductance $\left(\mathrm{g}_{\mathrm{m}}\right)$}

It is the ratio of change in drain current $\left(\Delta \mathrm{I}_{\mathrm{D}}\right)$ to the change in gate source voltage $\left(\Delta \mathrm{V}_{\mathrm{GS}}\right)$ at constant drain source voltage $\left(V_{D S}\right)$ it's measured in $\mathrm{mA} /$ volt or micromho, usually expressed as [12]:

$\mathrm{g}_{\mathrm{m}}=\frac{\Delta \mathrm{I}_{\mathrm{D}}}{\Delta \mathrm{V}_{\mathrm{GS}}}$ at constant $\mathrm{V}_{\mathrm{DS}}$

\subsubsection{Amplification factor $(\boldsymbol{\mu})$}

It is the ratio of change in drain source voltage $\left(\Delta \mathrm{V}_{\mathrm{DS}}\right)$ to the change in gate source voltage $\left(\Delta \mathrm{V}_{\mathrm{GS}}\right)$ at constant drain current, expressed as:

$\mu=\frac{\Delta \mathrm{V}_{\mathrm{DS}}}{\Delta \mathrm{V}_{\mathrm{GS}}}$ at constant $\mathrm{I}_{\mathrm{D}}$

The relationship among parameters can be established as under:

$\mu=\frac{\Delta \mathrm{V}_{\mathrm{DS}}}{\Delta \mathrm{V}_{\mathrm{GS}}}$

Multiplying the numerator and denominator on R.H.S by $\Delta \mathrm{I}_{\mathrm{D}}$ we have,

$\mu=\frac{\Delta V_{D S}}{\Delta V_{G S}} \times \frac{\Delta I_{D}}{\Delta I_{D}}=\frac{\Delta V_{D S}}{\Delta I_{D}} \times \frac{\Delta I_{D}}{\Delta V_{G S}}$

$\therefore \mu=r_{d} \times g_{m}$

For the proper operation of $\mathrm{n}$ channel JFET, gate must be negative w.r.t. source [11], [12].

This can be achieved either by inserting a battery in the gate circuit or by biasing circuit. The latter method is preferred because batteries are costly and require frequent replacement.

\subsection{JFET with Voltage-Divider Bias}

The operating point for the circuit of d.c. conditions of JFET amplifier is $V_{D S}, I_{D}$.

But from the simulations results of $2 \mathrm{~N} 4416 \mathrm{n}$ channel JFET at gate shorted condition $\left(\mathrm{V}_{\mathrm{GS}}=0\right) \mathrm{I}_{\mathrm{D}}=\mathrm{I}_{\mathrm{DSS}}=9.711 \mathrm{~mA}$ and $V_{\mathrm{DS}(\max )}=10 \mathrm{~V}$ these are the operating point of the circuit. It is often desirable to bias a JFET near the midpoint of its transfer characteristic curve where $I_{D}=I_{D S S} / 2$ for the drain voltage at midpoint $\left(V_{D}=V_{D D} / 2\right)$ [11], [12]. To produce the desired voltage drop the value $R_{D}$ and $R_{S}$ can be calculated using the following expression:

$\mathrm{V}_{\mathrm{DD}}=\mathrm{I}_{\mathrm{D}} \mathrm{R}_{\mathrm{D}}+\mathrm{V}_{\mathrm{D}}$

$\therefore \mathrm{R}_{\mathrm{D}}=\frac{\mathrm{V}_{\mathrm{DD}}-\mathrm{V}_{\mathrm{D}}}{\mathrm{I}_{\mathrm{D}}}=\frac{(10-5) \mathrm{V}}{4.86 \mathrm{~mA}}=1.03 \mathrm{k}^{\prime} \Omega$

From figure7 the graph of drain current against drain source voltage we have $\mathrm{V}_{\mathrm{GS}}$ (off) $=-2.75 \mathrm{~V}$

$\mathrm{I}_{\mathrm{D}}=\mathrm{I}_{\mathrm{DSS}}\left[1-\frac{\mathrm{V}_{\mathrm{GS}}}{\mathrm{V}_{\mathrm{GS} \text { (off })}}\right]^{2}$

$4.86=9.711\left\lceil 1+\frac{\mathrm{V}_{\mathrm{GS}}}{2.75}\right\rceil^{2}$

$\therefore \mathrm{V}_{\mathrm{GS}}=-0.8055$

Recall, $\mathrm{V}_{\mathrm{G}}=\mathrm{V}_{\mathrm{GS}}+\mathrm{V}_{\mathrm{S}}$

$\mathrm{V}_{\mathrm{S}}=\mathrm{V}_{\mathrm{G}}-\mathrm{V}_{\mathrm{GS}}$, But $\mathrm{V}_{\mathrm{G}}=0$, at shorted gate condition

$\therefore \mathrm{V}_{\mathrm{S}}=0-(-0.8055)=0,8055 \mathrm{~V}$, But $\mathrm{V}_{\mathrm{S}}=\mathrm{I}_{\mathrm{D}} \mathrm{R}_{\mathrm{S}}$

$\therefore \mathrm{R}_{\mathrm{S}}=\frac{\mathrm{V}_{\mathrm{S}}}{\mathrm{I}_{\mathrm{D}}}=\frac{0.8055 \mathrm{~V}}{4.86 \mathrm{~mA}}=0.17 \mathrm{k}^{\prime} \Omega$

Also $R_{1}$ and $R_{2}$ can be calculated as follows

$\mathrm{V}_{\mathrm{DD}}=\mathrm{I}_{1} \mathrm{R}_{1}+\mathrm{V}_{\mathrm{G}}$ 
$\mathrm{R}_{1}=\frac{\mathrm{V}_{\mathrm{DD}}-\mathrm{V}_{\mathrm{G}}}{\mathrm{I}_{1}}$ but $\mathrm{I}_{1}=\mathrm{I}_{2}$

$\mathrm{R}_{1}=\frac{\mathrm{V}_{\mathrm{DD}}-\mathrm{V}_{\mathrm{G}}}{\mathrm{I}_{2}}$ and $\mathrm{V}_{2}=\mathrm{I}_{2} \mathrm{R}_{2}=\mathrm{V}_{\mathrm{G}}$

$I_{2}=\frac{V_{G}}{R_{2}}$

Where $\mathrm{V}_{\mathrm{G}}=\mathrm{V}_{\mathrm{GS}}+\mathrm{V}_{\mathrm{S}}=0.8055+4.86 \mathrm{~mA} \times 0.17 \mathrm{k}^{\prime} \Omega=0.8262 \mathrm{~V}$ and $\mathrm{R}_{2}=1 \mathrm{M}^{\prime} \Omega$ usually selected

$\therefore \mathrm{I}_{2}=\frac{0.8262 \mathrm{~V}}{1 \mathrm{M}^{\prime} \Omega}=0.0000008262=0.8262 \mu \mathrm{A}, \mathrm{R}_{1}=\frac{10-0.8262}{0.8262 \mu \mathrm{A}}=11 \mathrm{k}^{\prime} \Omega$

$\therefore \mathrm{R}_{1}=11 \mathrm{k}^{\prime} \Omega$ and $\mathrm{R}_{2}=1 \mathrm{M}^{\prime} \Omega$

This is the d.c. equivalent circuit which will determine the operating point (d.c. bias levels) for the circuit while in an a.c. equivalent circuit which determines the output voltage and hence voltage gain of the circuit. Here the designer intentionally selects capacitors that are large enough to appear as short circuit to the a.c signal [12]. In this case an electrolytic capacitor $\mathrm{C}_{\text {in }}(\approx 10 \mu \mathrm{F})$ is used to couple the signal to the base of the transistor, a source bypass capacitor $C_{S}(\approx 100 \mu \mathrm{F})$ is used in parallel with $\mathrm{R}_{\mathrm{S}}$ to provide a low reactance path to the amplified a.c. signal and a coupling capacitor $\mathrm{C}_{\mathrm{C}}(\approx 10 \mu \mathrm{F})$ couples one stage of amplification to the next stage. The complete JFET amplifier circuit with voltage divider biasing of $2 \mathrm{~N} 4416 \mathrm{n}$ - channel common source configuration transistor is shown in Figure 2 and Figure 3.

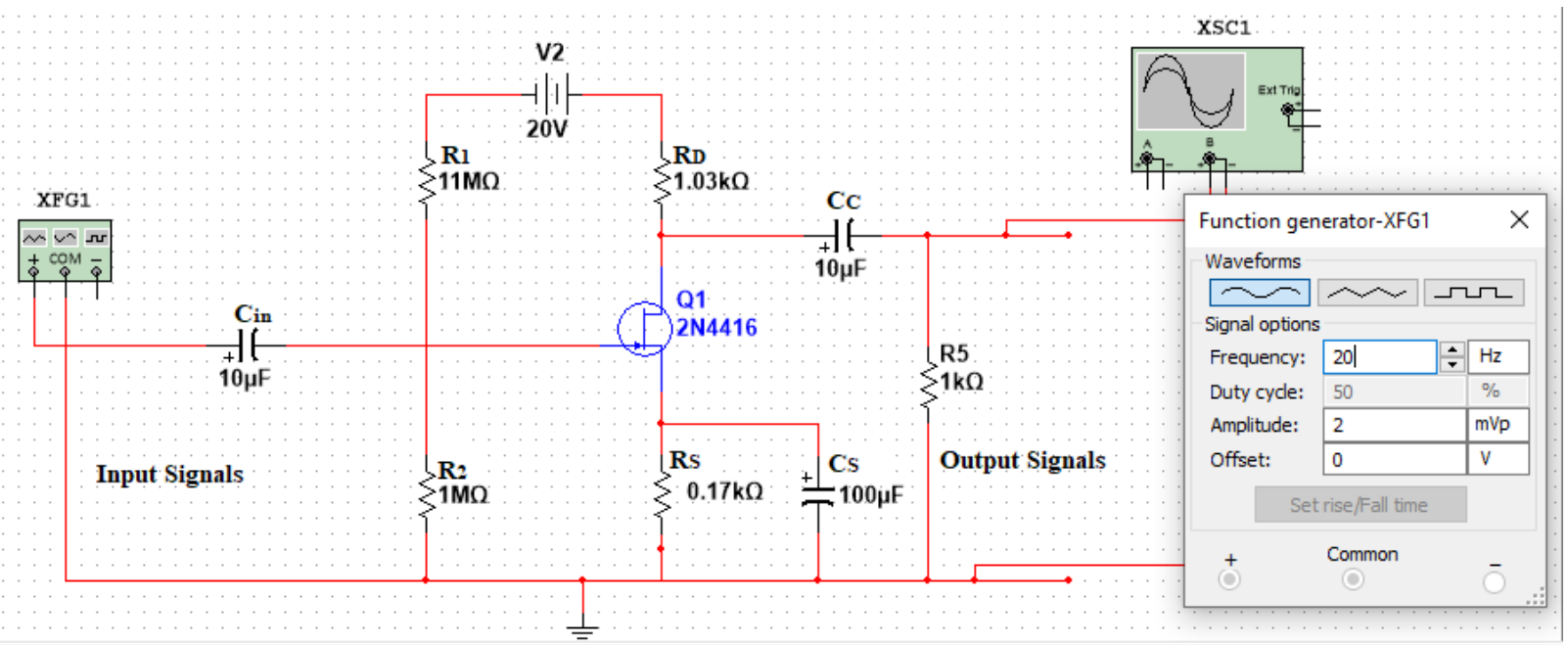

Figure 2: The complete circuit of 2N4416 n channel JFET common source configuration transistor loaded amplifier with voltage divider biasing

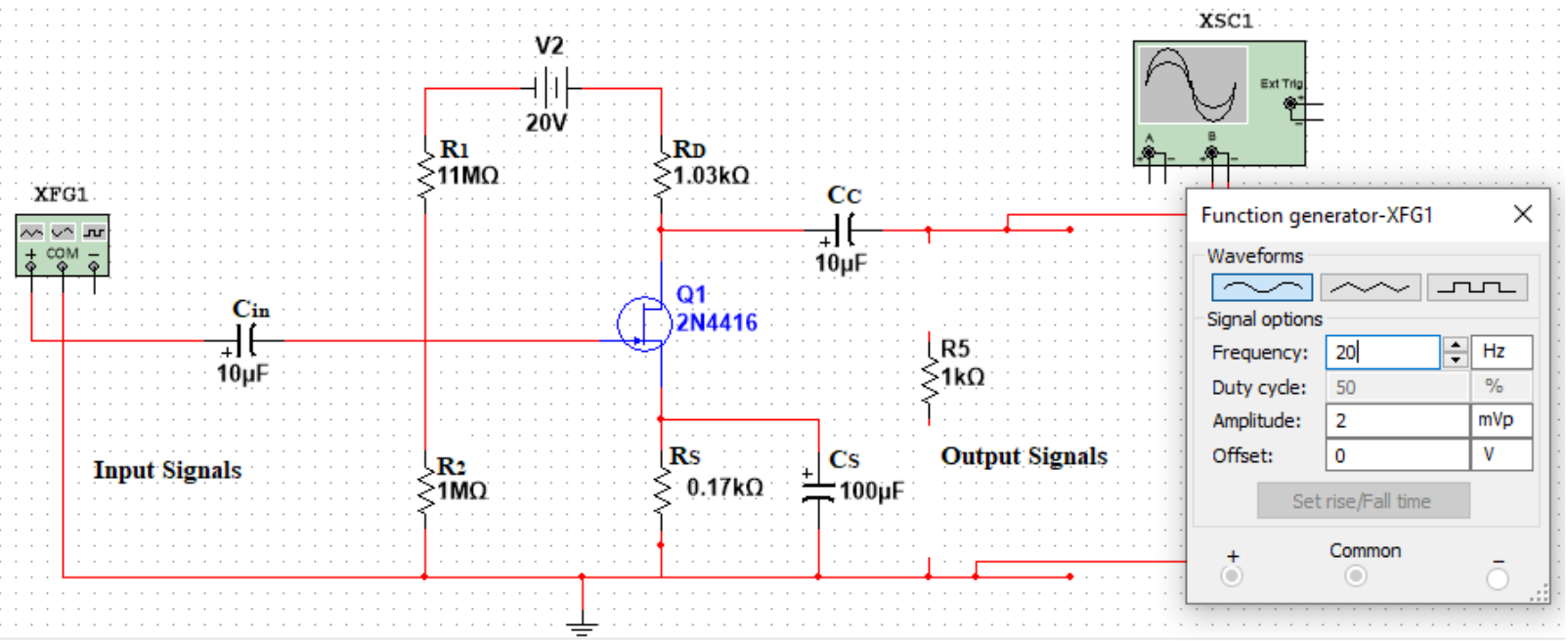

Figure 3: The complete circuit of $2 \mathrm{~N} 4416 \mathrm{n}$ channel JFET common source configuration transistor unloaded amplifier with voltage divider biasing 


\subsection{Voltage Gain of JFET Amplifier}

The voltage gain of this amplifier can be calculated mathematically as follows; let $R_{1} \| R_{2}$ be replaced by a single resistance $R_{T}$. Similarly, $R_{D} \| R_{L}$ and can be replaced by a single resistance $R_{A C}$ (= total a.c. drain resistance) [12]. Then output voltage $\left(V_{\text {out }}\right)$ is given by:

$\mathrm{V}_{\text {out }}=\mathrm{i}_{\mathrm{d}} \mathrm{R}_{\mathrm{AC}}$

Recall, $\mathrm{g}_{\mathrm{m}}=\frac{\Delta \mathrm{I}_{\mathrm{D}}}{\Delta \mathrm{V}_{\mathrm{GS}}}$ or $\frac{\mathrm{i}_{\mathrm{d}}}{\mathrm{V}_{\mathrm{gs}}}$

$\mathrm{i}_{\mathrm{d}}=\mathrm{g}_{\mathrm{m}} \mathrm{V}_{\mathrm{gs}}$, But $V_{g s}=V_{\text {in }}$

$\therefore \mathrm{V}_{\text {out }}=\mathrm{g}_{\mathrm{m}} \mathrm{V}_{\text {in }} \mathrm{R}_{\mathrm{AC}}$ And $\frac{\mathrm{V}_{\text {out }}}{\mathrm{V}_{\text {in }}}=\mathrm{g}_{\mathrm{m}} \mathrm{R}_{\mathrm{AC}}$

Where $\frac{\mathrm{V}_{\text {out }}}{\mathrm{V}_{\text {in }}}=$ voltage gain $\left(\mathrm{A}_{\mathrm{v}}\right)$ of the amplifier

$\therefore$ valtage gain $A_{v}=g_{m} R_{A C}$ for loaded and $g_{m} R_{D}$ for unloaded amplifier without source resistance.

With source resistance can be calculated as follows:

$\mathrm{V}_{\text {in }}=\mathrm{V}_{\mathrm{gs}}+\mathrm{i}_{\mathrm{d}} \mathrm{R}_{\mathrm{s}}$

$\mathrm{V}_{\text {out }}=\mathrm{i}_{\mathrm{d}} \mathrm{R}_{\mathrm{D}}$

Voltage gain, $A_{v}=\frac{V_{\text {out }}}{V_{\text {in }}}=\frac{i_{d} R_{D}}{V_{g s}+i_{d} R_{s}}=\frac{g_{m} V_{g s} R_{D}}{V_{g s}+g_{m} V_{g s} R_{S}}=\frac{g_{m} V_{g s} R_{D}}{V_{g s}\left(1+g_{m} R_{S}\right)}\left(i_{d}=g_{m} V_{g s}\right)$

$\therefore A_{v}=\frac{g_{m} R_{D}}{1+g_{m} R_{S}}=\frac{g_{m} R_{D}}{1+g_{m} R_{S}}$ for unloaded and $\frac{g_{m} R_{A C}}{1+g_{m} R_{S}}$ for loaded amplifier with source resistance

\subsection{SIMULATION}

\subsection{Determinations of the important terms}

The following important terms were determined, shorted gate drain current $\left(\mathrm{I}_{\mathrm{DSs}}\right)$, Pinch off voltage $\left(\mathrm{V}_{\mathrm{P}}\right)$ and Gate source cut off voltage $\left(\mathrm{V}_{\mathrm{GS} \text { (off) }}\right)$, the proposed simulation circuit diagram at shorted gate condition is shown in Figure 4.

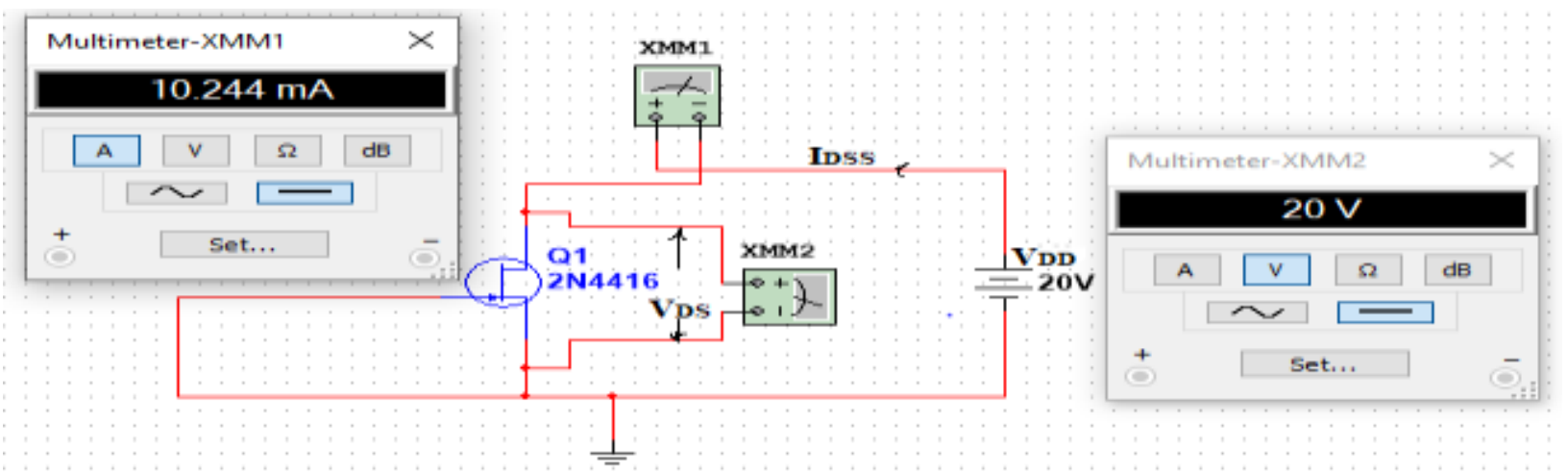

Figure 4: The simulation circuit diagram of 2N4416 n channel JFET with common source at shorted gate condition

\subsection{Determinations of the main parameters}

The following main parameters were determined, a.c drain resistance $\left(\mathrm{r}_{\mathrm{d}}\right)$, transconductance $\left(\mathrm{g}_{\mathrm{m}}\right)$ and amplification factor $(\mu)$, the proposed simulation circuit diagram is shown in Figure 5 and Figure 6.

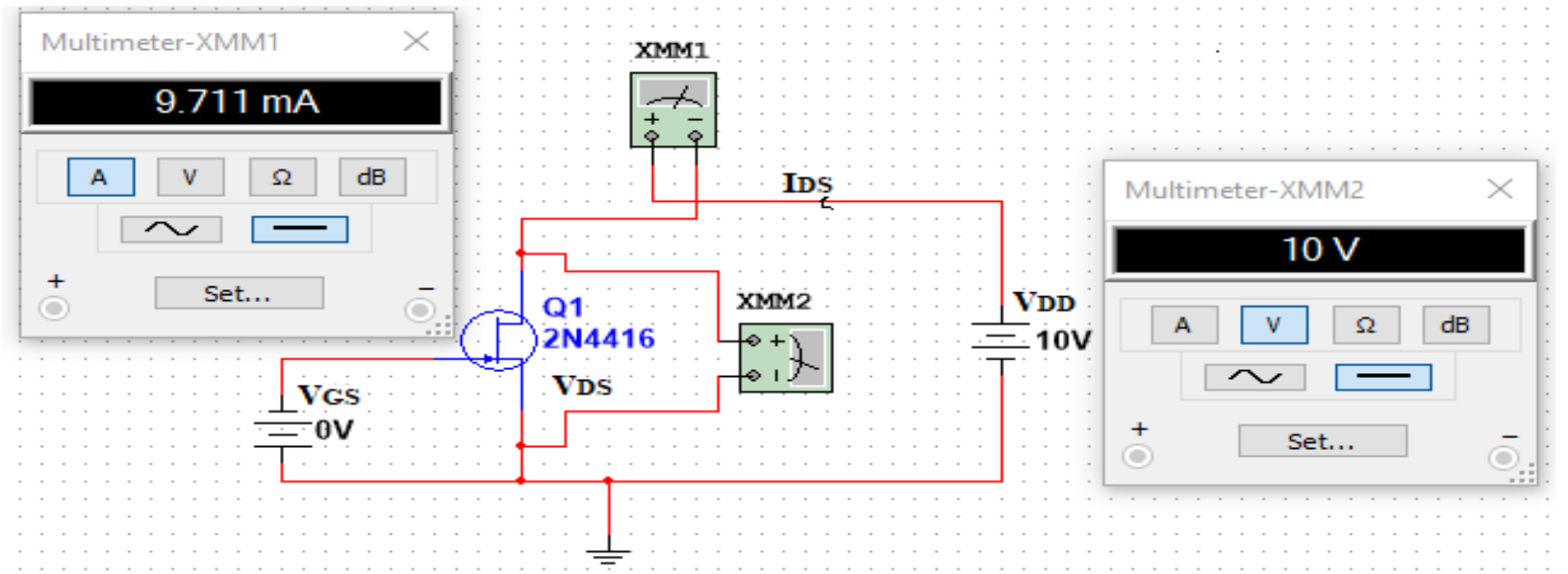

Figure 5: Shown the simulation circuit diagram of 2 N4416 JFET with common source at $\mathrm{V}_{\mathrm{GS}}=0$ 


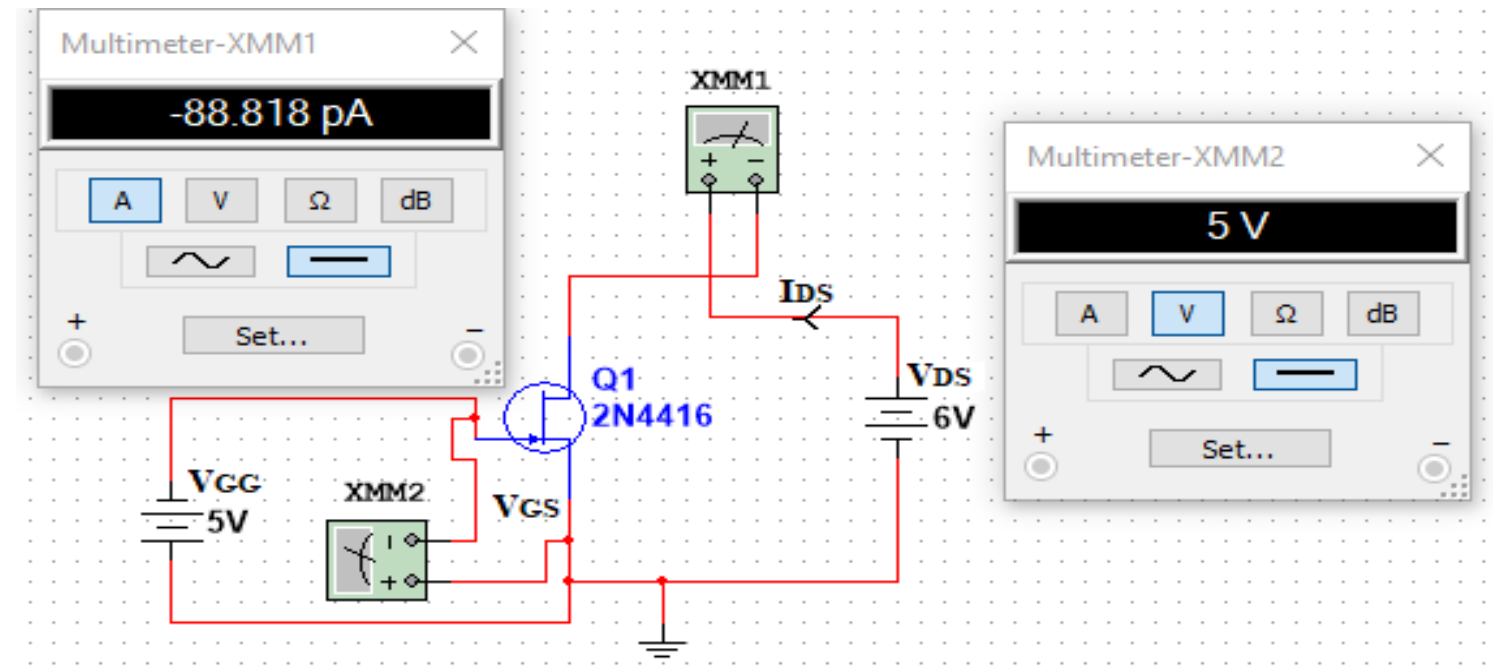

Figure 6: The simulation circuit diagram of $2 \mathrm{~N} 4416 \mathrm{JFET}$ with common source at $\mathrm{V}_{\mathrm{DS}}=6 \mathrm{~V}$

\subsection{Determination of frequency response of the amplifier}

The frequency response and bandwidth of the amplifier at $V_{i n}=2 \mathrm{mV}$ and $V_{D D}=+20 \mathrm{~V}$ varying the frequency of the input signal were determined; the proposed simulation circuit diagram is shown in Figure 7.

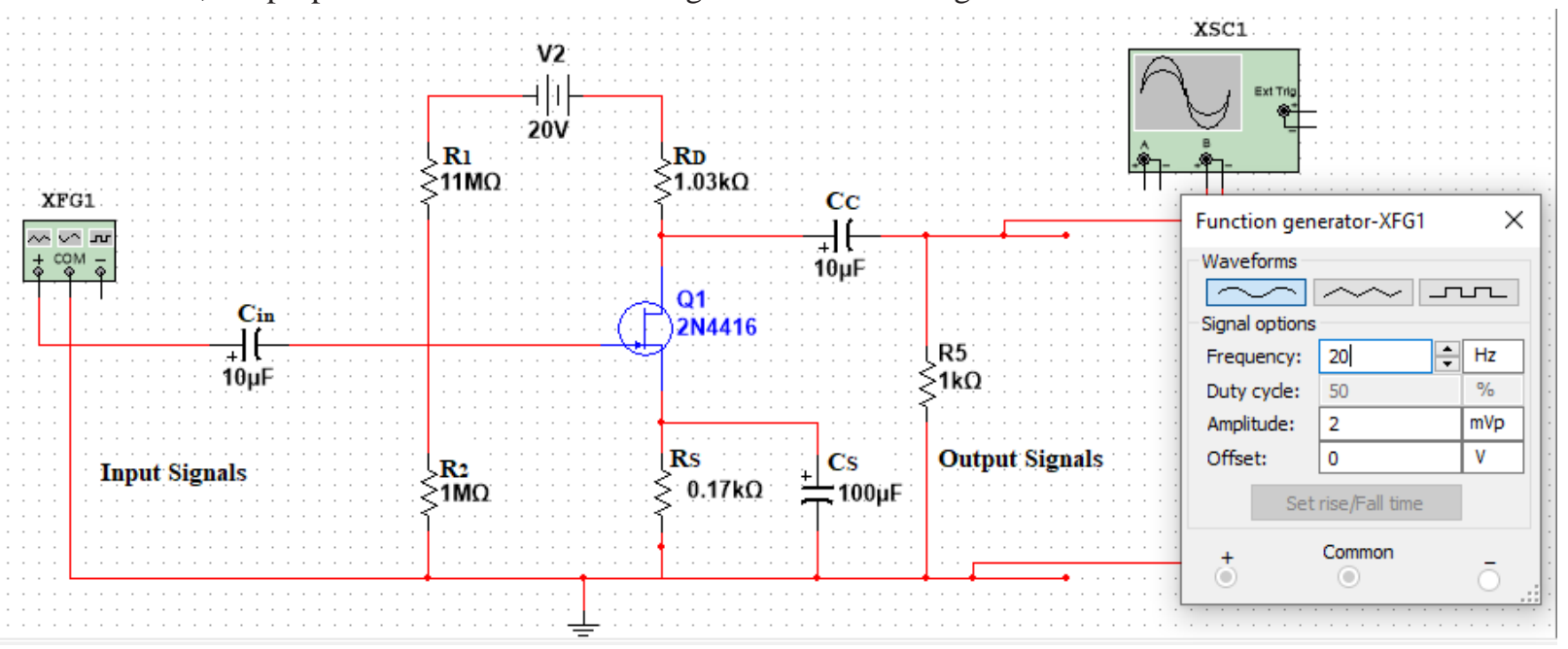

Figure 7: The simulation circuit diagram of loaded $2 N 4416 \mathrm{n}$ channel JFET amplifier with common source at $\mathrm{V}_{\mathrm{in}}=$ $2 \mathrm{mV}$ and $\mathrm{V}_{\mathrm{DD}}=+20 \mathrm{~V}$

\subsection{RESULTS AND DISCUSSION}

\subsection{The important terms results and discussion}

At shorted gate condition, varying the drain voltages $\left(\mathrm{V}_{\mathrm{DD}}\right)$ from $0.25,0.5,0.75,1$ to $10 \mathrm{~V}$ the corresponding values of drain current $\left(I_{D}\right)$ and drain source voltage $\left(V_{D S}\right)$ were obtained, the graph of $I_{D}$ against $V_{D S}$ was plotted, the shorted gate drain current $\left(\mathrm{I}_{\mathrm{DSS}}\right)$, pinch off voltage $\left(\mathrm{V}_{\mathrm{P}}\right)$ and gate source cut off voltage $\left(\mathrm{V}_{\mathrm{GS}}\right.$ (off) $)$ were determined graphically as shown in Figure 8 . 


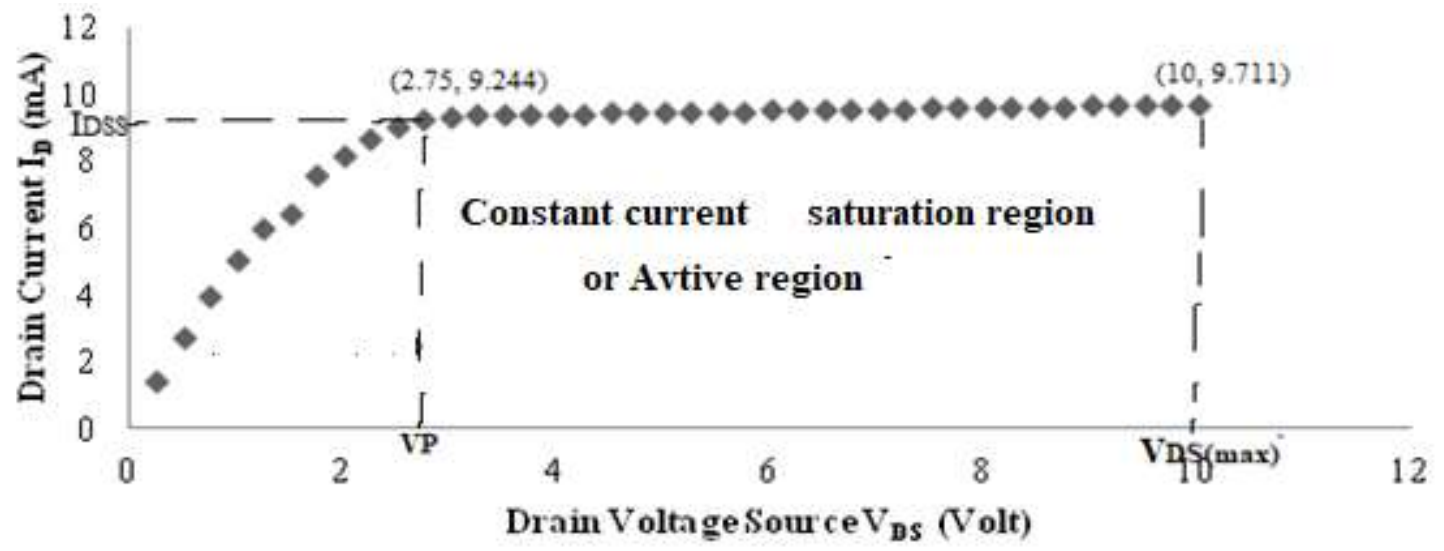

Figure 8: The graph of drain current against drain source voltage

Looking from the graph the maximum shorted gate drain current $\left(I_{D S S}\right)$ which have been measured under shorted gate condition is $9.244 \mathrm{~mA}$, the minimum drain source voltage at which the drain current becomes constant is $2.75 \mathrm{~V}$, this is the pinch off voltage $\left(\mathrm{V}_{\mathrm{P}}\right)$ and gate source cut off voltage $\left(\mathrm{V}_{\mathrm{GS} \text { (off) }}\right)$ is $-2.75 \mathrm{~V}$

Since the two values are always equal and opposite, the region between $V_{P}$ and $V_{D S}$ (max) is called constant current or saturation region as long as $V_{D S}$ is kept within this range the $I_{D}$ will remain almost constant for a constant value of $V_{G S}$.

4.2 The main parameters results and discussion

At constant gate source voltage $\left(\mathrm{V}_{\mathrm{GS}}=0\right)$ varying the drain voltages $\left(\mathrm{V}_{\mathrm{DD}}\right)$ from $1,2,3,4$ to $5 \mathrm{~V}$ the corresponding values of drain current $\left(I_{D}\right)$ and drain source voltage $\left(V_{D S}\right)$ were obtained, the graph of $I_{D}$ against $V_{D S}$ was plotted and the a.c drain resistance $\left(r_{d}\right)$ was determined from the graph as shown in Figure 9.

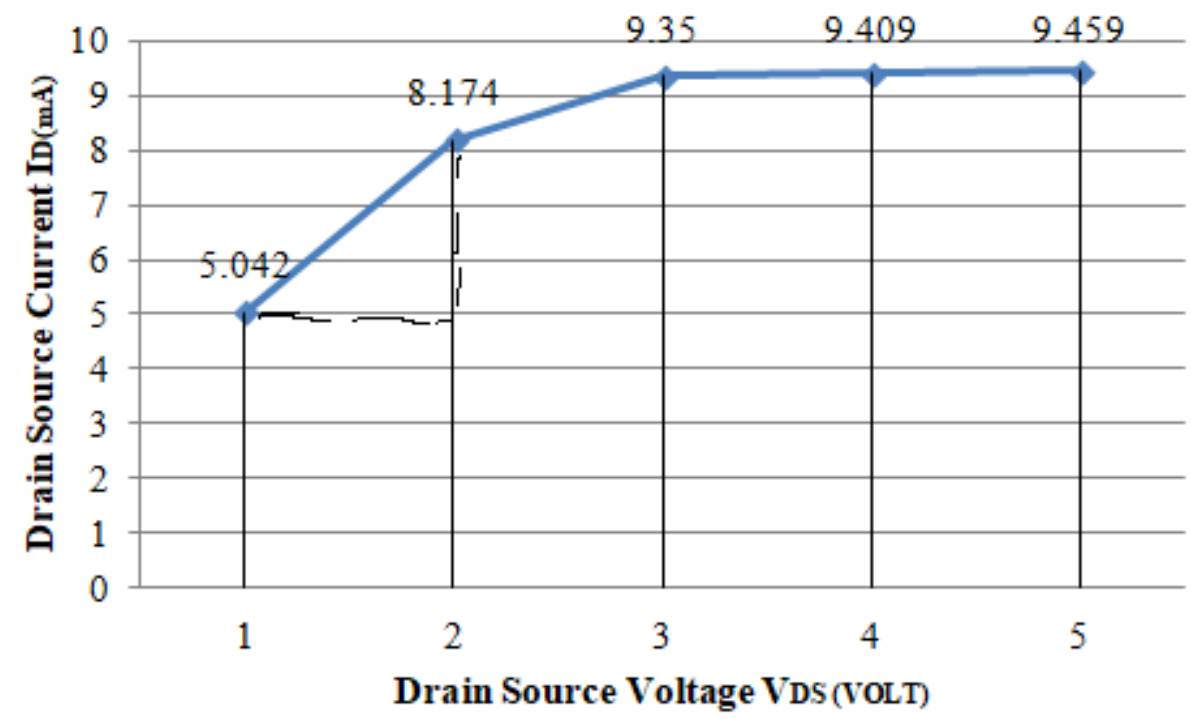

Figure 9: The graph of drain current $\left(I_{D}\right)$ against drain source voltage $\left(V_{D S}\right)$ for a.c drain resistance $\left(r_{d}\right)$ determination

Looking at the first data point from the left to right of figure 8 graph the following readings were obtained:

Change in drain source voltage, $\Delta \mathrm{V}_{\mathrm{DS}}=2-1=1 \mathrm{~V}$

Change in drain current, $\Delta \mathrm{I}_{\mathrm{D}}=8.174-5.042=3.132 \mathrm{~mA}$

$\therefore$ a. c drain resistance $\left(\mathrm{r}_{\mathrm{d}}\right)=\frac{\Delta \mathrm{V}_{\mathrm{DS}}}{\Delta \mathrm{I}_{\mathrm{D}}}=\frac{1 \mathrm{~V}}{3.132 \mathrm{~mA}}=0.3193 \mathrm{k}^{\prime} \Omega$ or $319.3^{\prime} \Omega$

Also at constant drain source voltage $\left(\mathrm{V}_{\mathrm{DS}}=6 \mathrm{~V}\right)$ varying the gate voltages $\left(\mathrm{V}_{\mathrm{GG}}\right)$ from $0,-1,-2,-3,-4$, to $-5 \mathrm{~V}$, the corresponding values of drain current $\left(\mathrm{I}_{\mathrm{D}}\right)$ and drain source voltage $\left(\mathrm{V}_{\mathrm{GS}}\right)$ were obtained, the graph of $\mathrm{I}_{\mathrm{D}}$ against $\mathrm{V}_{\mathrm{GS}}$ was plotted and transconductance $\left(\mathrm{g}_{\mathrm{m}}\right)$ was determined graphically as shown in Figure 10. 


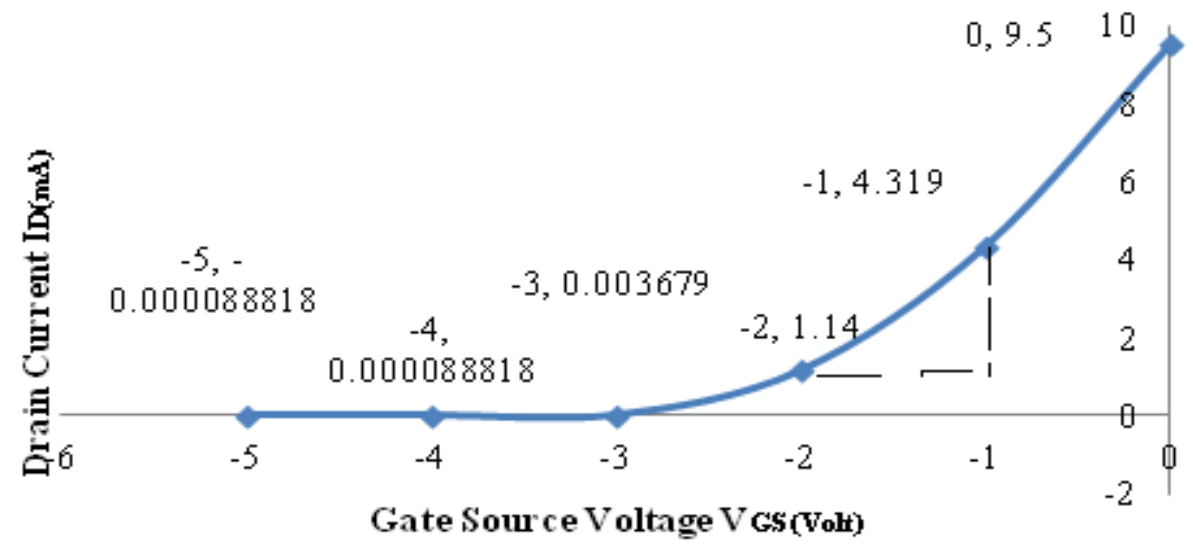

Figure 10: The graph of drain current $\left(I_{D}\right)$ against gate source voltage $\left(V_{G S}\right)$ for transconductance $\left(g_{m}\right)$ determination Looking from the graph of figure 9 the following readings were obtained:

Change in gate source voltage, $\Delta \mathrm{V}_{\mathrm{GS}}=2-1=1 \mathrm{~V}$

Change in drain current, $\Delta \mathrm{I}_{\mathrm{D}}=4.319-1.14=3.179 \mathrm{~mA}$

$\therefore$ transconductance $\left(\mathrm{g}_{\mathrm{m}}\right)=\frac{\Delta \mathrm{I}_{\mathrm{D}}}{\Delta \mathrm{V}_{\mathrm{GS}}}=\frac{3.179 \mathrm{~mA}}{1 \mathrm{~V}}=3.179 \mathrm{~mA} / \mathrm{V}=3179 \mu \mathrm{mho}$ and amplification factor $\mu=r_{d} \times g_{m}=319.3 \times 3179 \times 10^{-6}=1.0150547$ this shows the higher amplification factor.

\subsection{The frequency response results of the amplifier and discussion}

At constant applied voltages, $V_{\text {in }}=2 \mathrm{mV}$ and $V_{D D}=+20 \mathrm{~V}$ varying the frequency of the input signal the corresponding amplitude variation in output voltages at different values frequency were determined and the graph of gains against frequencies was plotted as shown in Figure 11.

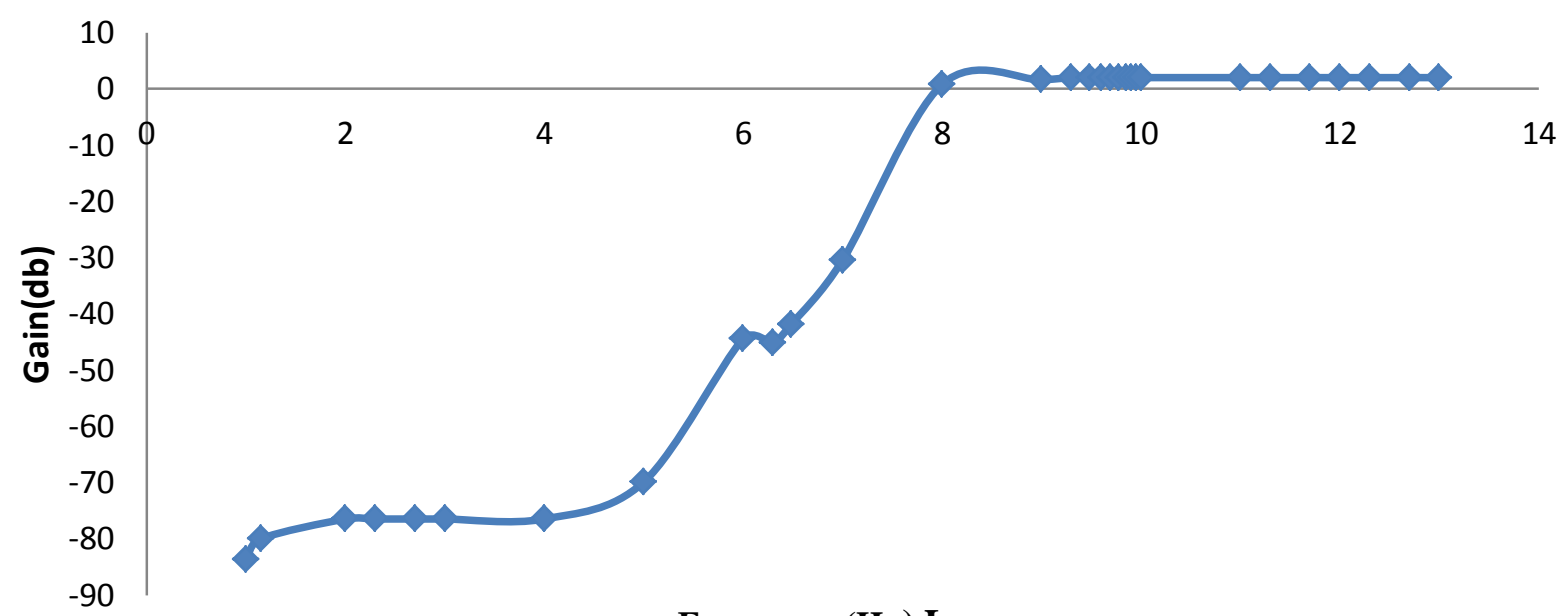

Frequency (Hz) Long

Figure11: The graph of gains against frequencies

Looking at first data point from the left to the right of the horizontal axis of figure 10 graph, the voltage gain of the amplifier increases with increases of the signal frequency, it is because reactance of the capacitors in the circuit changes with signal frequency and hence affects the output voltage and it is clear that from the frequency of $\log 8$ which is lower cut off frequency to the infinity the gain is maximum and equal this tell the large bandwidth of the amplifier.

\section{CONCLUSION}

The 2 N4416 $\mathrm{n}$ channel JFET single stage amplifier was designed in order to analyze the circuit, important terms and main parameters were determined, the frequency respond and bandwidth of the amplifier was also determined and discussed graphically, the results characterized amplifier with large bandwidth and low voltage gain, using Multisim 14.2 simulator. 


\section{REFERENCE}

[1]. Ehiagwina, F. O., Kehinde, O. O., Afolabi, L. O., Onawola, H. J., \& Iromini, N. A. (2016). Applications, Prospects and Challenges of Silicon Carbide Junction Field Effect Transistor (SIC JFET). International Journal of Advances in Telecommunications, Electrotechnics, Signals and Systems, 5(3), 133-141.

[2]. Buevich, M., Rajagopal, N., \& Rowe, A. (2013). Hardware assisted clock synchronization for real-time sensor networks. Paper presented at the 2013 IEEE 34th Real-Time Systems Symposium.

[3] Prasad, R. (2021). Transistor Bipolar Junction (BJT) and Field-Effect (FET) Transistor Analog and Digital Electronic Circuits: : Springer, (pp. 457-581).

[4] Yazeer, M. J. (2016). Comparative study of silicon nanowire fet-simulation and experimental. Gombak, Selangor: International Islamic University Malaysia, 2016.

[5] Fu, R., Grekov, A., Hudgins, J., Mantooth, A., \& Santi, E. (2011). Power SiC DMOSFET model accounting for nonuniform current distribution in JFET region. IEEE Transactions on Industry Applications, 48(1), 181-190.

[6] Popelka, S., Hazdra, P., Sharma, R., Záhlava, V., \& Vobecký, J. (2014). Effect of neutron irradiation on high voltage 4HSiC vertical JFET characteristics: characterization and modeling. IEEE Transactions on Nuclear Science, 61(6), 30303036.

[7] Jin, S., Zhang, D., Wang, C., \& Gu, Y. (2017). Optimized design of space solar array simulator with novel three-port linear power composite transistor based on multiple cascaded SiC-JFETs. IEEE Transactions on Industrial Electronics, 65(6), 4691-4701.

[8] Alnasser, E. (2020). A novel low output offset voltage charge amplifier for piezoelectric sensors. IEEE Sensors Journal, 20(10), 5360-5367.

[9]. Narang, R., Saxena, M., Gupta, R., \& Gupta, M. (2013). Impact of temperature variations on the device and circuit performance of tunnel FET: a simulation study. IEEE transactions on Nanotechnology, 12(6), 951-957.

[10] Taeb, A., Abdipour, A., \& Mohammadi, A. (2007). Modeling and analysis of a nonlinear fully distributed FET using FDTD technique. AEU-International Journal of Electronics and Communications, 61(7), 444-452.

[11]. Oxner, E. S. (2020). Fet Technology and Application: CRC Press, ISBN: 9781000147315.

[12]. Mehta,V.K., \& Mehta, R. (2008). Principles of Electronics, Revised Eleventh Edition. S. Chand \& company LTD, India, ISBN: 81-219-2450-2. 